American Journal of Biochemistry and Biotechnology 5 (4): 202-209, 2009

ISSN 1553-3468

(C) 2009 Science Publications

\title{
A New Polyoxypregnane Glycoside from the Roots of Dregea volubilis (L.f) Benth. ex Hook. $f$ and its Chondroprotective Effect
}

\author{
${ }^{1}$ Saksri Sanyacharernkul, ${ }^{2}$ Akanit Itghiarbha, ${ }^{2}$ Prachya Kongtawelert, ${ }^{3}$ Puttinan Meepowpan, \\ ${ }^{4}$ Narong Nuntasaen and ${ }^{1}$ Wilart Pompimon \\ ${ }^{1}$ Laboratory of Natural Products and Center for Innovation in Chemistry, \\ Department of Chemistry, Faculty of Science, Lampang Rajabhat University, \\ Lampang 52100 Thailand \\ ${ }^{2}$ Thailand Excellence Center for Tissue Engineering, Department of Biochemistry, \\ Faculty of Medicine, Chiang Mai University, Chiang Mai, 50200 Thailand \\ ${ }^{3}$ Center for Innovation in Chemistry, Department of Chemistry, Faculty of Science, \\ Chiang Mai University, Chiang Mai 50200 Thailand \\ ${ }^{4}$ The Forest Herbarium, Department of National Park Wildlife and Plant Conservation, \\ Ministry of Natural Resources and Environment, Bangkok 10900 Thailand
}

\begin{abstract}
Problem statement: Dregea genus (Asclepiadaceae) is well known for the rich of steroid pregnane contents and these plants are famous for the potential to be applied as alternative biological activities. Dregea volubilis is the only species of Dregea genus in Thailand. The chemical and biological investigations of this plant are interesting to bioassay-guided fractionation, particularly chondroprotective effect. Approach: The research was carried out to extract, isolate, purify and elucidate structure of the active compound from the roots Dregea volubilis. Both of the solvent extracts and isolated compound were evaluated with kinds of chondroprotection. i.e., S-GAG), HA, UA and production of matrix metalloproteinase-2 (MMP-2). Results: Polyoxypregnane glycoside (PGG) or 12-0-benzoyl-8, 11-ditigloyl-3 $\beta, 8 \beta, 11 \alpha, 12 \beta, 14 \beta$-pentahydroxy-pregn-14-ol, 20-one,-3-0-methyl- $\beta$ D-allopyranosyl $(1 \rightarrow 4)-\beta$-D-thevetopyranoside was isolated from the active ethyl acetate extract of the roots Dregea volubilis. The spectroscopic techniques were provided for success in structure determination. In addition, a new compound was the most powerful to biological activities. Chondroprotective effect of PPG on the degradation of sulfated glycosaminoglycan (S-GAG), hyaluronan (HA), uronic acid (UA) and production of matrix metalloproteinase-2 (MMP-2) in interleukin-1 $\beta$ (IL-1 $\beta$ )-stimulated porcine articular cartilage were also assessed. PGG was interestingly effective in reducing IL-1 $\beta$ induced S-GAG, HA release from cartilage explant and MMP-2 activity. Furthermore, PPG can reverse effect of IL-1 $\beta$-reduced the levels of uronic acid remaining in cartilage tissue. Conclusion: The PGG was possessed a potent chondroprotective activity using the IL-1 $\beta$ stimulated cartilage explant model. Therefore, it is possible to use this compound as a new pharmacological agent for the management of degenerative joint diseases.
\end{abstract}

Key words: Dregea volubilis, Polyoxypregnane glycoside (PGG), Chondroprotective effect

\section{INTRODUCTION}

Dregea volubilis (Asclepiadaceae) is found in the tropical zone and South East Asia, the plant is used in folk medicine as an antifebrile and emetic ${ }^{[1]}$. Moreover, this plant has used as a remedy to treat haematemesis, aphrodisiac, sore throat, abdomial tumours, appetizer, carminative, heals carbuncles, eczema, asthma and antidote for poison $^{[2]}$. The alcoholic extract of this plant effect on central nervous system, as well as anticancer activity against sarcoma 180 in the mice ${ }^{[3]}$. Extensive survey of the genus Dregea by Smittinand indicated the presence of one specie in Thailand which was determined by The Royal Forest Department of Thailand, especially, Dregea volubilis is scattered widely throughout in all parts of Thailand ${ }^{[4]}$. The

Corresponding Author: Wilart Pompimon, Laboratory of Natural Products and Center for Innovation in Chemistry, Department of Chemistry, Faculty of Science, Lampang Rajabhat University, Lampang 52100 Thailand Tel/Fax: +665-3241052 
Dregea volubilis grows in a form of woody climber. The leaves are ovate, or somewhat rounded, $7.5-15 \mathrm{~cm}$ long, 5-10 cm wide. The flowers are green, about $1 \mathrm{~cm}$ radius. Moreover, the seeds are elliptic, concave, smooth, shining, shining sharp-edged ${ }^{[3]}$. Dregea volubilis (BKF 136098) has various local names in Thailand. It is called 'Kra thong ma ba', 'Khun chun sunak ba', 'Khruea khao khlon', 'Nguan mu', 'Khruea thao mu' and 'Hua $\mathrm{mu}^{[3]}$ '. Additionally, in the traditional Thai medicinal used the leaves as an application to boil and abscess. On the other hand, the roots and tender stalks are considered emetic and expectorant. Moreover, the young roots are cut and exuding juice is inserted into the nose to cause sneezing ${ }^{[5]}$. Chemical investigation on this plant was focused on pregnane derivatives which this class of compounds have been reported to be rich in Asclepiadaceae family, particularly C-21 steroidal glycosides of polyhydroxypreg-type glycoside ${ }^{[6]}$. As a result of our on-going studies of the chemical constituents of the roots of Dregea volubilis, herein we report the isolation and structural determination of a new polyoxypregnane glycosides and its bioassayguided fractionation on cartilage degradation induced by interleukin-1 $\beta$ (IL-1 $\beta$ ) or chondroprotective effects. The results of this study will bring about alternative pharmacological agents for arthritis disease.

\section{MATERIALS AND METHODS}

General procedures: Melting point was measured on a BÜchi 322 micromelting point apparatus and had to be uncorrected. IR spectrum was recorded as $\mathrm{KBr}$ pellets using a Shimadzu 8900 FTIR spectrophotometer. The ${ }^{1} \mathrm{H}$ and ${ }^{13} \mathrm{C}$ NMR (1D and 2D) spectra were recorded at $400 \mathrm{MHz}$ and $100 \mathrm{MHz}$ respectively using a DPX on a BrÜker DPX 400 spectrometer in $\mathrm{CDCl}_{3}$ as an internal standard. ESIMS (positive mode) were obtained by using a Finnigan LC-Q Advantage Thermoquest spectrometer equipped with Xcalibur software. Silica gel 60 (Merck, 70-230 mesh) was used for column chromatography; while TLC analysis was carried out on silica gel $\mathrm{GF}_{254}$ precoated plates with detection using UV detector.

Plant material: Roots of Dregea volubilis were collected in Lampang Province, Thailand, in February, 2008. They were identified by Forest Herbarium. A voucher specimen (BKF no. 136098) has been deposited at the Forest Herbarium, Department of National Park, Wildlife and Plant Conservation, Ministry of Natural Resources and Environment, Bangkok, Thailand.
Extraction and isolation: Air-dried powdered roots of Dregea volubilis $(2.8 \mathrm{~kg})$ were successively defatted with hexane ( $7 \mathrm{~L} \times 3$ days $\times 6$ times) and then sequential extracted consecutively at room temperature with ethyl acetate $(6.5 \mathrm{~L} \times 3$ days $\times 8$ times), acetone $(6 \mathrm{~L} \times 3$ days $\times 9$ times) and methanol (5.5 L $\times 3$ days $\times 5$ times), followed by filtration. The filtrates were combined and evaporated to dryness under reduced pressure to afford $61.52,116.5,29.33$ and $176.63 \mathrm{~g}$ of the residues, respectively. The extracts were submitted for bioassays. Preliminary biological investigation for cartilage degradation of the four extracts was carried out by our collaborator from Chiang Mai University of Thailand. Chondroprotective tests were performed on inducing by interleukin-1 $\beta$ (IL-1 $\beta$ ). It was also found that the ethyl acetate extract displayed strong activity in S-GAG release, HA release and Uronic acid remaining. From the bioassay-guided fractionation, the ethyl acetate fraction was firstly separated by column chromatography. The ethyl acetate extract (116.50 g) was subjected to a coarse separation on a silica gel column (700 g), eluting with various proportions of ethyl acetate-n-hexane, followed by the increasing amount of methanol in ethyl acetate and finally with methanol. Fractions (1000 mL each) were collected and combined on the basis of TLC behavior. The solvents were evaporated to dryness to afford eight fractions $\left(\mathrm{F}_{1^{-}}\right.$ $\left.F_{8}\right)$. Fraction $F_{5}(10.35 \mathrm{~g})$, eluted by $30 \%$ ethyl acetaten-hexane, was obtained as gray powder solid. Furthermore, the $\mathrm{F}_{5}$ was rechromatographed on a silica column to yield the white solid which was recrystallized from methanol to give purified white powder $0.56 \mathrm{~g}$. Solids were collected and identified as polyoxypregnane glycosides (PPG).

Explant culture: Porcine articular cartilage was dissected from the metacarpophalangeal joints of 20-24 weeks-old pigs obtained from a local abattoir $4 \mathrm{~h}$ after slaughter. Cartilage explants were cultured in a 24 well tissue culture plates with a serum-free medium (Dulbecco's modified Eagle's medium, DMEM) containing 100 units $\mathrm{mL}^{-1}$ penicillin and $100 \mu \mathrm{g} \mathrm{mL}^{-1}$ streptomycin ${ }^{[7]}$. For all experiments, the explants were maintained in a humidified incubator with $5 \% \mathrm{CO}_{2}$ at $37^{\circ} \mathrm{C}$ for $24 \mathrm{~h}$ (Day 0) before treating with each extract. Cartilage degradation was induced with recombinant human IL-1 $\beta\left(10 \mu \mathrm{g} \mathrm{mL}^{-1}\right)$ in the present or absence of various concentration of each extract $\left(6.25-25 \mu \mathrm{g} \mathrm{mL}^{-1}\right)$ for 3 days (Day 3) in order to observe their chondroprotective effects. Treatments were performed with triplicate using tissue from the same animal donor. 
Measurement of sulfated glycosaminoglycan concentration: The sulfated glycosaminoglycan (SGAG) concentration in the medium was determined by Dimethylmethylene Blue (DMMB) assay using shark cartilage chondroitin sulfate C (Sigma-Aldish ${ }^{\circledR}$, USA) as a standard modify from Farndale et al. ${ }^{[8]}$. The dye solution was added to the medium sample, with standard and appropriate blank solution was also measured absorbance at $525 \mathrm{~nm}$ by a micro-plate reader spectrophotometer. The S-GAG release from cartilage due to incubation by IL-1 $\beta$ were calculated by:

$\begin{aligned} \mathrm{S}-\mathrm{GAG} \text { release }(\%)= & {[(\text { medium from D3-mediam }} \\ & \text { from D0)/(medium from } \\ & \mathrm{D} 0)] \times 100\end{aligned}$

Measurement of hyaluronan concentration: HA content in condition medium was quantified using the competitive inhibition-based Enzyme-Linked Immunosorbent Assay (ELISA) method as previously described ${ }^{[9]}$. The HABP-hyaluronan complexes were then detected using b-HABP (biotinylated HABP) and HRP (horseradish peroxidase)-mouse monoclonal antibiotin followed by a chromogenic reaction. The assay was carried out on MaxiSorb 96-well Nunc-Immuno Plates precoated overnight with $100 \mu \mathrm{g} \mathrm{mL} \mathrm{m}^{-1} \mathrm{HABP}$ in coating buffer. After three washes in PBS-Tween 20 and blocking in PBS supplemented with 1\% BSA for $1 \mathrm{~h}$. Following washing, $100 \mu \mathrm{L}$ of the mixture of hyaluronan standards $\left(0-10,000 \mu \mathrm{g} \mathrm{mL} \mathrm{m}^{-1}\right)$ (Healon; Pharmacia Pharmaceutical AB, Sweden) and samples, in b-HABP (1:200) were added and mixtures were incubated for $1 \mathrm{~h}$ at $25^{\circ} \mathrm{C}$. Then, after removing excess b-HABP, the b-HABP bound to the hyaluronan trapped by the HA-coated plates was detected by incubation for $1 \mathrm{~h}$ with HRP-mouse monoclonal anti-biotin (Sigma), followed by the addition of $100 \mathrm{~mL}$ of OPD (Ophenylene-diamine) substrate solution (Sigma) for 15 mins. Then, $50 \mu \mathrm{L}$ of $4 \mathrm{M} \mathrm{H}_{2} \mathrm{SO}_{4}$ was added and the absorbance ratio at 492/690 $\mathrm{nm}$ was measured. The hyaluronan content in the conditioned media was calculated by comparing with a standard curve made from known concentrations of hyaluronan.

Measurement of uronic acid: Hexosamine and uronic acid are the components of the repeating unit of all Glycosaminoglycans (GAGs). Uronic acid is widely determined as the representative of GAGs in biological substances. This assay measures uronic acid by releasing the monosaccharide using acid hydrolysis ${ }^{[10]}$. For a standard curve, 0 to $2.4 \mu \mathrm{g}$ of glucuronic acid lactone or sample $(5 \mu \mathrm{L})$ in up to $400 \mu \mathrm{L}$ of water was added to a test tube. Concentrated sulfuric acid-borate reagent $(2.5 \mathrm{~mL})$ was added to the tube and mixed. The tubes were then incubated at $100^{\circ} \mathrm{C}$ in a water bath for $5 \mathrm{~min}$ and cooled to room temperature in ice bath. The solution of $0.1 \% \mathrm{~m}$-phenylphenol $(50 \mu \mathrm{L})$ was added and mixed. The uronic acid reaction was required incubation at room temperature for $15 \mathrm{~min}$. The absorbance of the pink to red color was read in a spectrophotometer at 540 $\mathrm{nm}$ against distilled water blank. The \% uronic acid remaining was calculated using:

[(UA of control-UA of treatment)/UA of control] $\times 100$

Gelatin zymography: MMP-2 activity was determined by gelatin zymography using $0.1 \mathrm{mg} \mathrm{mL} \mathrm{m}^{-1}$ gelatin (Sigma-Aldrich $^{\circledR}$, USA) as a substrate in $10 \%$ SDS polyacrylamide gel ${ }^{[11]}$. After electrophoresis, gels were washed three times with $2.5 \%$ Triton $\mathrm{X}-100, \mathrm{pH} 7.5$ and then incubated overnight at $37^{\circ} \mathrm{C}$ in $0.2 \%$ Brij 35, 5

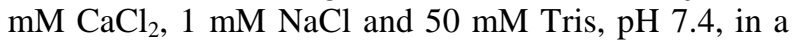
closed container. Gels were then stained with $0.1 \%$ Coomassie R-250 in $\mathrm{MeOH}: \mathrm{H}_{2} \mathrm{O}: \mathrm{AcOH}(5: 4: 1 \mathrm{v} / \mathrm{v})$ and destained for 30 mins with $\mathrm{MeOH}: \mathrm{H}_{2} \mathrm{O}: \mathrm{AcOH}$ $(5: 4: 1 \mathrm{v} / \mathrm{v})$. Finally, the gelatinolytic activity was analyzed by Scion image densitometer.

\section{RESULTS}

Chemical structure elucidation: In this investigation, some of biological activity of Dregea volubilis has been tested, whereby; hexane, ethyl acetate, acetone and methanol extract were assayed for their chondroprotective effect. The active acetate extract was carried out for purification, separation, crystallization and structure elucidation of the isolated polyoxypregnane glycoside (PGG). The structure has been established on the basis of spectral and chemical evidence. It is worth nothing that the data from spectroscopic techniques, especially the ${ }^{1} \mathrm{H},{ }^{13} \mathrm{H}-1 \mathrm{D}$ and 2D NMR were performed on the accurate molecular structure (Table 1 and 2).

Table $1:{ }^{13} \mathrm{C}$ NMR, ${ }^{1} \mathrm{H}$ NMR data of the agylcone moietie and ${ }^{1} \mathrm{H}-{ }^{13} \mathrm{C}$, ${ }^{1} \mathrm{H}-{ }^{1} \mathrm{H}$ correlations exhibited in the $2 \mathrm{D}$ NMR spectra in $\mathrm{CDCl}_{3}$

\begin{tabular}{|c|c|c|c|c|}
\hline Carbon & $\delta{ }^{13} \mathrm{C}(\mathrm{DEPT})$ & $\delta{ }^{1} \mathrm{H}(\mathrm{J} \mathrm{Hz})$ & $\begin{array}{l}\text { HMBC } \\
\text { correlation }\end{array}$ & $\begin{array}{l}\text { COSY } \\
\text { correlation }\end{array}$ \\
\hline 1 & $32.42\left(\mathrm{CH}_{2}\right)$ & 1.38 (obsc.) & $\mathrm{C}-3$ & $\mathrm{H}-2$ \\
\hline 2 & $27.99\left(\mathrm{CH}_{2}\right)$ & 1.72 (obsc.) & - & $\mathrm{H}-1$ \\
\hline 3 & $69.72(\mathrm{CH})$ & $3.36(\mathrm{~m})$ & Thevetose C-1 & $\mathrm{H}-2$ \\
\hline 4 & $38.69\left(\mathrm{CH}_{2}\right)$ & 1.58 (obsc.) & C-3, Thevetose C-1 & - \\
\hline 5 & $44.38(\mathrm{CH})$ & 1.38 (obsc.) & $\mathrm{C}-3$ & H-6 \\
\hline 6 & $31.23\left(\mathrm{CH}_{2}\right)$ & 1.11 (obsc.) & C-4, C-5, C-7 & $\mathrm{H}-5, \mathrm{H}-7$ \\
\hline 7 & $32.42\left(\mathrm{CH}_{2}\right)$ & 1.38 (obsc.) & C-8, 8-Tigloyl C-1 & H-6 \\
\hline 8 & $71.53(\mathrm{C})$ & - & - & - \\
\hline 9 & $52.72(\mathrm{CH})$ & 2.0 (obsc.) & C- $8, C-12$ & - \\
\hline 10 & $39.41(\mathrm{C})$ & - & - & - \\
\hline 11 & $78.85(\mathrm{CH})$ & $5.19(\mathrm{~d}, 10.11)$ & 11-Tigloyl C-1 & H-12 \\
\hline 12 & $67.83(\mathrm{CH})$ & $5.45(\mathrm{~d}, 10.11)$ & 12-Benzoyl C-1 & $\mathrm{H}-11$ \\
\hline 13 & $47.22(\mathrm{C})$ & - & - & - \\
\hline 14 & $65.82(\mathrm{C})$ & - & - & - \\
\hline 15 & $31.65\left(\mathrm{CH}_{2}\right)$ & 1.11 (obsc.) & C-17 & H-16 \\
\hline 16 & $29.68\left(\mathrm{CH}_{2}\right)$ & 1.27 (obsc.) & C-15 & H-15 \\
\hline 17 & $52.70(\mathrm{CH})$ & 2.0 (obsc.) & C-14, C- 20 & - \\
\hline 18 & $11.61\left(\mathrm{CH}_{3}\right)$ & 1.27 (obsc.) & C-11, C-13 & - \\
\hline 19 & $12.72\left(\mathrm{CH}_{3}\right)$ & 1.13 (obsc.) & $\mathrm{C}-4, \mathrm{C}-5, \mathrm{C}-9$ & - \\
\hline 20 & $209.20(\mathrm{C})$ & - & - & - \\
\hline 21 & $31.23\left(\mathrm{CH}_{3}\right)$ & $1.94(\mathrm{~s})$ & C-20 & - \\
\hline
\end{tabular}


Am. J. Biochem. \& Biotech., 5 (4): 202-209, 2009

Table 2: ${ }^{13} \mathrm{C}$ NMR, ${ }^{1} \mathrm{H}$ NMR data of the sugar and tigloyl portion and ${ }^{1} \mathrm{H}-{ }^{13} \mathrm{C},{ }^{1} \mathrm{H}-{ }^{1} \mathrm{H}$ correlations exhibited in the 2D NMR spectra in $\mathrm{CDCl}_{3}$

\begin{tabular}{|c|c|c|c|c|}
\hline Carbon & $\delta{ }^{13} \mathrm{C}(\mathrm{DEPT})$ & $\delta{ }^{1} \mathrm{H}(\mathrm{J} \mathrm{Hz})$ & $\begin{array}{l}\text { HMBC } \\
\text { correlation }\end{array}$ & $\begin{array}{l}\text { COSY } \\
\text { correlation }\end{array}$ \\
\hline \multicolumn{5}{|c|}{ Thevetose } \\
\hline 1 & $97.26(\mathrm{CH})$ & $4.59(\mathrm{~d}, 2.46)$ & $\mathrm{C}-2$ & $\mathrm{H}-2$ \\
\hline 2 & $76.46(\mathrm{CH})$ & 3.58 (obsc.) & C-4 & $\mathrm{H}-1, \mathrm{H}-3$ \\
\hline 3 & $72.77(\mathrm{CH})$ & 3.27 (obsc.) & C-5 & - \\
\hline 4 & $88.35(\mathrm{CH})$ & $2.97(\mathrm{~m})$ & C-6, Allomethylose C-1 & - \\
\hline 5 & $70.29(\mathrm{CH})$ & $3.36(\mathrm{~m})$ & $\mathrm{C}-1, \mathrm{C}-4, \mathrm{C}-6$ & - \\
\hline 6 & $17.99\left(\mathrm{CH}_{3}\right)$ & 1.38 (obsc.) & $\mathrm{C}-4, \mathrm{C}-5$ & - \\
\hline \multicolumn{5}{|c|}{ Allomethylose } \\
\hline 1 & $101.71(\mathrm{CH})$ & $4.50(\mathrm{~d}, 2.46)$ & C-5, Thevetose C-4 & $\mathrm{H}-2$ \\
\hline 2 & $72.77(\mathrm{CH})$ & $3.50(\mathrm{~m})$ & $\mathrm{C}-1$ & $\mathrm{H}-1$ \\
\hline 3 & $80.74(\mathrm{CH})$ & $3.79(\mathrm{~m})$ & $\mathrm{C}-2, \mathrm{C}-\mathrm{OCH}_{3}$ & - \\
\hline 4 & $71.51(\mathrm{CH})$ & 3.68 (obsc.) & $\mathrm{C}-3$ & - \\
\hline 5 & $71.14(\mathrm{CH})$ & 3.68 (obsc.) & $\mathrm{C}-3$ & - \\
\hline 6 & $17.46\left(\mathrm{CH}_{3}\right)$ & 1.30 (obsc.) & $\mathrm{C}-5$ & - \\
\hline $\mathrm{OMe}$ & $62.36\left(\mathrm{CH}_{3}\right)$ & 3.68 (obsc.) & $\mathrm{C}-3$ & - \\
\hline \multicolumn{5}{|c|}{ 8-Tigloyl } \\
\hline $1^{\prime}$ & $165.80(\mathrm{C})$ & - & - & - \\
\hline $2^{\prime}$ & $128.86(\mathrm{C})$ & - & - & - \\
\hline $3^{\prime}$ & $138.60(\mathrm{CH})$ & 4.50 (obsc.) & - & $\mathrm{H}-5^{\prime}$ \\
\hline $4^{\prime}$ & $11.34\left(\mathrm{CH}_{3}\right)$ & 1.38 (obsc.) & $\mathrm{C}-3$ & - \\
\hline $5^{\prime}$ & $14.38\left(\mathrm{CH}_{3}\right)$ & 1.47 (obsc.) & C- $1, \mathrm{C}-2, \mathrm{C}-3$ & - \\
\hline \multicolumn{5}{|c|}{ 11-Tigloyl } \\
\hline $1^{\prime}$ & $166.94(\mathrm{C})$ & - & - & - \\
\hline $2^{\prime}$ & $128.86(\mathrm{C})$ & - & - & - \\
\hline $3^{\prime}$ & $138.37(\mathrm{CH})$ & 4.50 (obsc.) & - & $\mathrm{H}-5^{\prime}$ \\
\hline $4^{\prime}$ & $11.61\left(\mathrm{CH}_{3}\right)$ & 1.67 (obsc.) & $\mathrm{C}-2, \mathrm{C}-3$ & - \\
\hline $5^{\prime}$ & $14.18\left(\mathrm{CH}_{3}\right)$ & 1.72 (obsc.) & $\mathrm{C}-2, \mathrm{C}-3$ & - \\
\hline \multicolumn{5}{|c|}{ 12-Benzoyl } \\
\hline 1 & $166.38(\mathrm{C})$ & - & - & \\
\hline 2 & $138.07(\mathrm{C})$ & - & - & \\
\hline 3 & $128.29(\mathrm{CH})$ & 7.38 (obsc.) & C-1, C-4 & $\mathrm{H}-4$ \\
\hline 4 & $129.40(\mathrm{CH})$ & $7.86(\mathrm{~m})$ & C-3, C-5 & H-3, H-5 \\
\hline 5 & $132.71(\mathrm{CH})$ & $7.51(\mathrm{~m})$ & C-4, C-6 & $\mathrm{H}-4$ \\
\hline 6 & $128.06(\mathrm{CH})$ & $7.18(\mathrm{~m})$ & C-5, C-7 & H-7 \\
\hline 7 & $128.18(\mathrm{CH})$ & $7.64(\mathrm{~m})$ & C-1, C-6 & H-6 \\
\hline
\end{tabular}

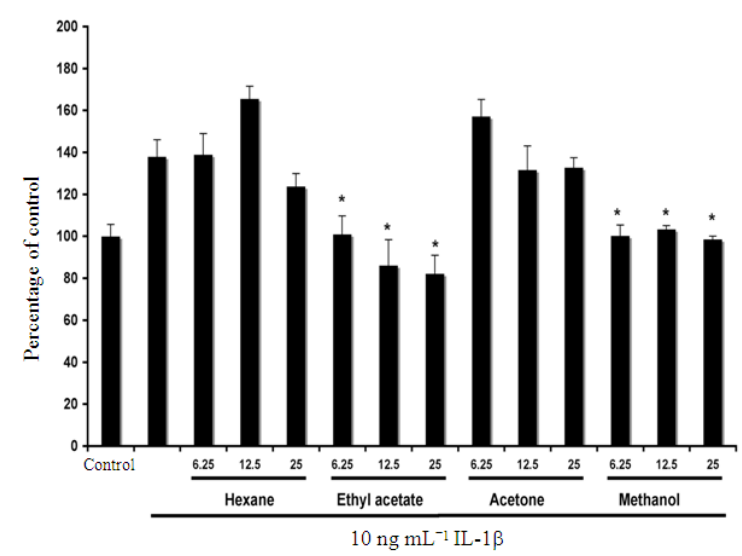

Fig. 1: Effect of Dregea volubilis extracts on S-GAG release in porcine cartilage explants. The explants were cultured with IL-1 $\beta\left(10 \mu \mathrm{g} \mathrm{mL}^{-1}\right)$ in absence and presence of Dregea volubilis; hexane, ethyl acetate, acetone and methanol extracts (at concentrate $6.25-25 \mu \mathrm{g} \mathrm{mL}^{-1}$ ) for 3 days. Media were collected and analyzed by dye-binding assay as described in above method. The values represent the means \pm SE from three independent experiments. *: $\mathrm{p}<0.05$ compared with the IL-1 $\beta$ control

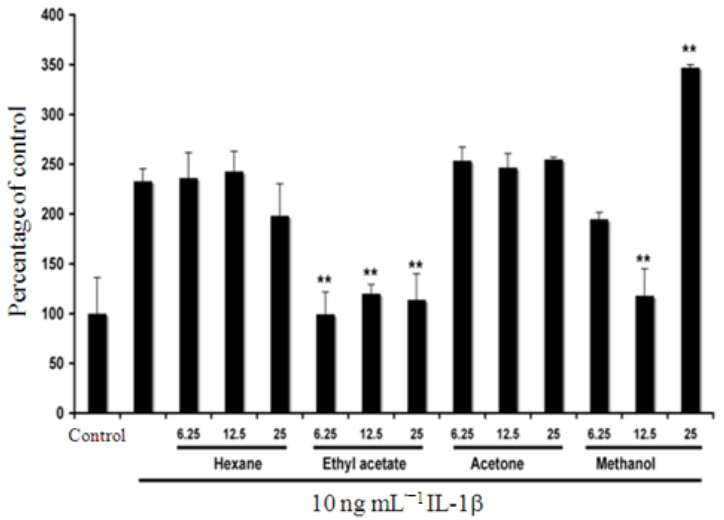

Fig. 2: Effect of Dregea volubilis extracts on HA release in porcine cartilage explants. The explants were cultured with IL-1 $\beta\left(10 \mu \mathrm{g} \mathrm{mL}^{-1}\right)$ in absence and presence of Dregea volubilis; hexane, ethyl acetate, acetone and methanol extracts (at concentrate 6.25-25 $\mu \mathrm{g} \mathrm{mL}^{-1}$ ) for 3 days. Media were collected and analyzed by HA-ELISA as described in above method. The values represent the means \pm SE from three independent experiments. $* *: \mathrm{p}<0.01$ compared with the IL-1 $\beta$ control

Chondroprotective effect of Dregea volubilis extracts in porcine cartilage explants: To investigate whether Dregea volubilis extracts (hexane, ethyl acetate acetone and methanol) inhibited effect of pro-inflammatory cytokine, IL-1 $\beta$ on the cartilage explants, we assessed extracellular matrix content in condition medium by DMMB assay, HA-ELISA and Uronic acid assay, respectively. As seen in Fig. 1, it was shown that the ethyl acetate and methanol extract decreased the levels of S-GAG concentration significantly when compared to the IL- $1 \beta$ treated group. Moreover, the ethyl acetate extract (all concentration) only inhibited the HA release (Fig. 2) and increased the uronic acid remaining in cartilage tissues at the highest concentration used (25 $\mu \mathrm{g} \mathrm{mL}^{-1}$ ) (Fig. 3). The ethyl acetate extract exhibited the high test chondroprotective activity in response to IL- $1 \beta$, compared with other extracts and were thus chosen for further studies.

Chondroprotective effect of PPG on porcine cartilage explants: To investigated the effects of PPG on the decreased levels of S-GAG and HA in the conditioned medium and increased levels of uronic acid remaining in cartilage tissues in response to IL-1 $\beta$, we determined as described above. The PPG induced 1.06-fold decrease in the S-GAG release was completely prevented at the highest concentration $(25 \mu \mathrm{g} \mathrm{mL}$ ) when the cartilage explants were cultured in the presence of IL-1 $\beta$ (Fig. 4a). 


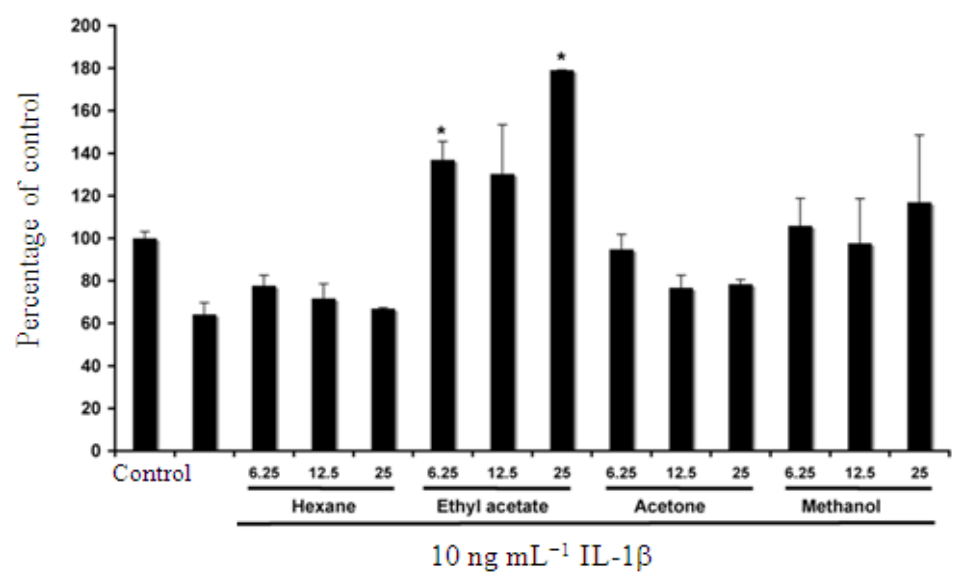

Fig. 3: Effect of Dregea volubilis extracts on uronic acid remaining in porcine cartilage tissues. The explants were cultured with IL-1 $\beta\left(10 \mu \mathrm{g} \mathrm{mL} \mathrm{m}^{-1}\right)$ in absence and presence of Dregea volubilis; hexane, ethyl acetate, acetone and methanol extracts (at concentrate $6.25-25 \mu \mathrm{g} \mathrm{mL}^{-1}$ ) for 3 days. Media were collected and analyzed by uronic acid assay as described in above method. The values represent the means \pm SE from three independent experiments. *: $\mathrm{p}<0.05$ compared with the IL-1 $\beta$ control

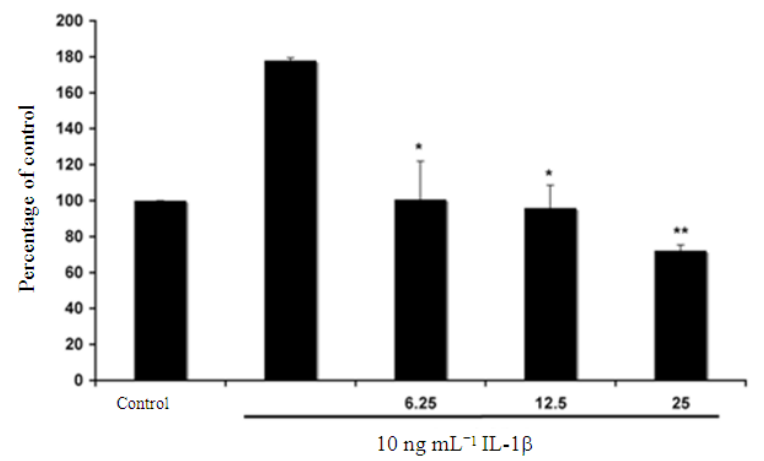

(a)

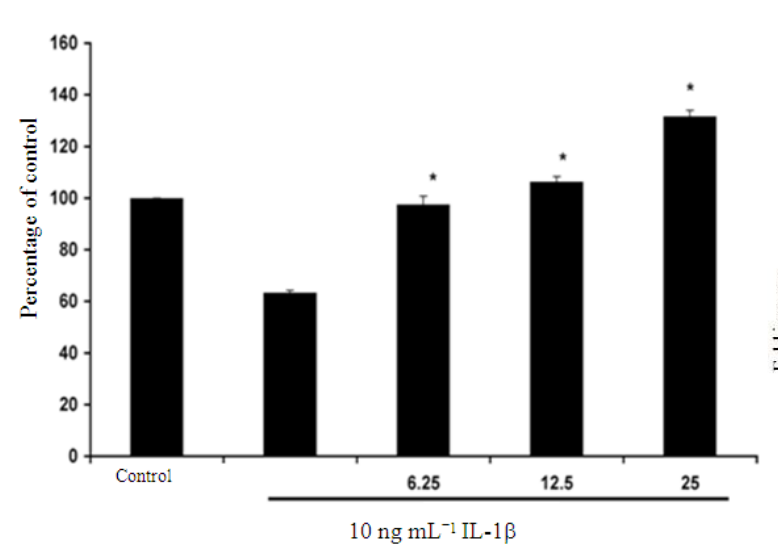

(c)

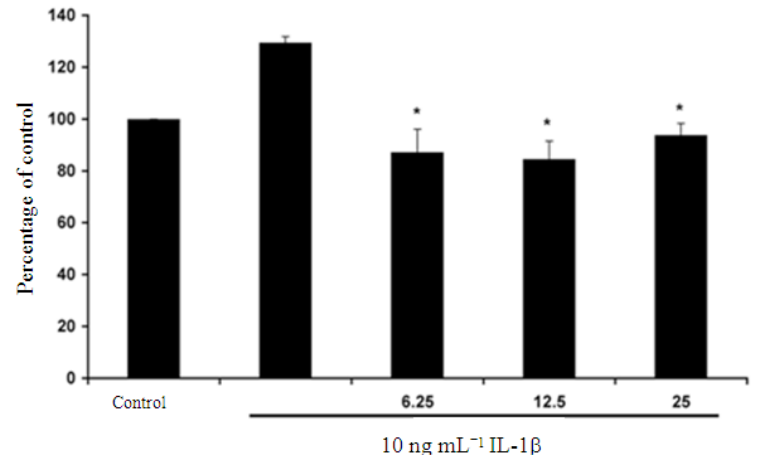

(b)

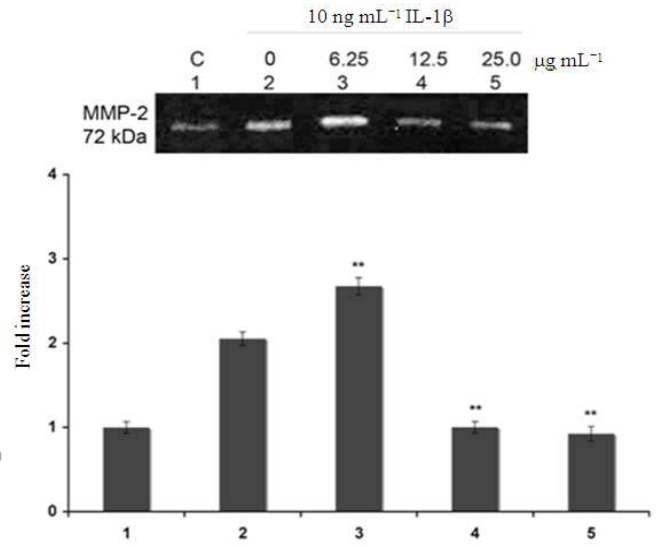

(d)

Fig. 4: Effect of Dregea volubilis extracts on S-GAG release (a), HA release (b), uronic acid remaining (c) and MMP-2 activity (d) in porcine cartilage explants. The explants were cultured with IL-1 $\beta\left(10 \mu \mathrm{g} \mathrm{mL}^{-1}\right)$ in absence and presence of PPG (at concentrate 6.25-25 $\mu \mathrm{g} \mathrm{mL}^{-1}$ ) for 3 day. Media were collected and analyzed as described in above methods. The values represent the means \pm SE from three independent experiments. *: $\mathrm{p}<0.05 ; * *$ : $<<0.01$ compared with the IL-1 $\beta$ control 
Furthermore, the levels of HA release were also suppressed when PPG was added to the culture (Fig. 4b) and PPG have significantly effect on the levels of uronic acid remaining in cartilage tissues (Fig. 4c). To examine whether PPG could inhibit the activities of the ECM degrading proteases, the effect of PPG on the secretion of MMP-2 were investigated by gelatin zymography. As shown in Fig. 4d, the PPG significantly reduced MMP-2 activity in a dosedependent manner.

\section{DISCUSSION}

Polyoxypregnane glycoside derivative (PPG) was isolated as a white solids powder, melting point 270$271.6^{\circ} \mathrm{C}$ and showed a quasimolecular ion peak at 956 $\mathrm{m} / \mathrm{z}[\mathrm{M}+\mathrm{H}]^{+}$in the positive ESIMS spectrum. Therefor, the molecular formula was established to be $\mathrm{C}_{51} \mathrm{H}_{72} \mathrm{O}_{17}$ by ESIMS and ${ }^{13} \mathrm{C}$ NMR analyses. The UV spectrum, $\lambda_{\max }^{\mathrm{EtOH}} \mathrm{nm} \quad(\log \varepsilon): 282 \quad(0.32), 225 \quad(1.11)$ of this compound exhibited the $\pi \rightarrow \pi^{*}$ of aromatic together with double bond and $\mathrm{n} \rightarrow \pi^{*}$ which belong to the carbonyl chromosphore. IR spectrum showed absorption bands due to hydroxyl $\left(3515,3420 \mathrm{~cm}^{-1}\right)$, ketone $\left(1699 \mathrm{~cm}^{-1}\right)$ and ester (1722 and $1276 \mathrm{~cm}^{-1}$ ) groups. The mass fragmentation ions in the mass spectrum of this compound at $\mathrm{m} / \mathrm{z} 956\left[\mathrm{M}^{+}\right], 914$ (4), 896 (5), 774 (100) (base peak), 691 (20), 595 (18), 551 (15), 361 (30), 343 (46) and 211 (9) were useful in obtaining the structure. The presence of the acetyl group was confirmed as evidenced by the fragment ion at $\mathrm{m} / \mathrm{z} 914$ for $\mathrm{C}_{49} \mathrm{H}_{69} \mathrm{O}_{16}{ }^{+}$. Furthermore, the fragment ion at $\mathrm{m} / \mathrm{z} 774$ was showed the benzoyl moiety in the structure (Fig. 5). Moreover, the one tigloyl group was confirmed by the fragment ion at $\mathrm{m} / \mathrm{z} 691$. The data from ${ }^{13} \mathrm{C}$ NMR spectra suggested a glycoside structure. The compound displayed 51 carbon signals in this ${ }^{13} \mathrm{C}$ NMR spectrum, of which 21 could be ascribed to the aglylcone pregnane moiety including one carbonyl carbon at $\delta 209.20$ (Table 1) which structure is mainly chemical constituent of this plant. The ${ }^{1} \mathrm{H}$ NMR of the glycone portion showed signals for three methyl groups at $\delta 1.13(3 \mathrm{H}$, obsc.), 1.27 (3H, obsc.) and $1.94(3 \mathrm{H}, \mathrm{s})$ and three signals at $\delta 3.36(\mathrm{~m}), 5.19(\mathrm{~d}, \mathrm{~J}=10.11 \mathrm{~Hz})$ and $5.45(\mathrm{~d}, \mathrm{~J}=10.11 \mathrm{~Hz})$ corresponding to secondary oxygenated carbons of the pregnane portion. The ${ }^{13} \mathrm{C}$ NMR chemical shift of all the hydrogenated carbons could be assigned ambiguously by the HMQC spectrum. The complete elucidation of the aglycone structure of this compound was achieved by the HMBC experiment. The HMBC correlations between the proton signal at $\delta 1.13(19-\mathrm{Me})$ and the carbon

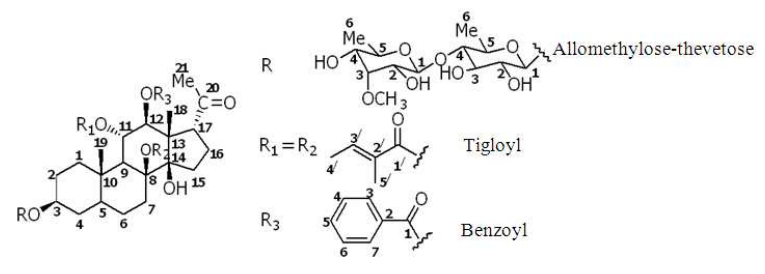

Fig. 5: Chemical structure of the PGG compound

resonances at $\delta 38.69(\mathrm{C}-4), 44.38(\mathrm{C}-5)$ and $52.72(\mathrm{C}-$ $9)$; the signal at $\delta 1.27(18-\mathrm{Me})$ and the carbon resonances at $\delta 78.85(\mathrm{C}-11)$ and $47.22(\mathrm{C}-13)$; the signal at $\delta 3.36(\mathrm{H}-3)$ and the carbon resonance $\delta 97.26$ (thevetose $\mathrm{C}-1)$; the signal at $\delta 5.19(\mathrm{H}-11)$ and the carbon resonance $\delta 166.94$ (11-tigloyl C-1); the signal at $\delta 5.45(\mathrm{H}-12)$ and the carbon resonance $\delta 166.38(12-$ benzoyl C-1) allowed us to deduce that the pregnane skeleton of this compound which was derivative of Volubiloside $^{[4]}$. Moreover, the sugar portion exhibited in the ${ }^{1} \mathrm{H}$ NMR spectrum signals corresponding to methyl groups at $\delta 1.30(3 \mathrm{H}$, obsc.) and $1.38(3 \mathrm{H}$, obsc.), one methoxy group at $\delta 3.68$ (3H, obsc.), as well as signals for two anomeric protons at $\delta 4.50(\mathrm{~m})$ and $4.59(\mathrm{~m})$. All these data indicated that this compound had two sugars at position-6 deoxy. From the ESIMS, COSY, HMQC and HMBC experiments showed the presence of one $\beta$-thevetopyranosyl unit linked to C-3 of the aglycone and one terminal $\beta$-allopyranosyl ${ }^{[12]}$ moiety. The conformation of the two sugars was exhibited by the ${ }^{1} \mathrm{H}$ NMR spectrum signals. The two doublets of one proton each at $\delta 4.59(\mathrm{~d}, \mathrm{~J}=2.46 \mathrm{~Hz})$ and $4.50(\mathrm{~d}, \mathrm{~J}=2.46 \mathrm{~Hz})$ which were assigned to anomeric protons of $\alpha$ - thevetose and $\alpha$-allomethylose, respectively. The small coupling constants of anomeric doublets showed that $\mathrm{D}$ - thevetose and $\mathrm{D}$-allomethylose were linked though $\alpha$-glycosidic linkage in their ${ }^{4} C_{1}$ and ${ }^{1} \mathrm{C}_{4}$ conformations ${ }^{[13]}$, respectively. In addition to the pregnane moiety, the ${ }^{1} \mathrm{H}$ NMR and ${ }^{13} \mathrm{C}$ NMR spectra of this compound showed signal due to benzoyl and two tigloyl groups. The benzoyl moiety was located at C-12 on the basis of the doublet of H-12 (5.45, d, J = $10.11 \mathrm{~Hz}$ ). This was confirmed by the results of HMBC experiments which showed clear long-range correlation peaks between the carbonyl carbon $(\mathrm{C}-1)$ and $\mathrm{H}-12$ of the aglycone. Moreover, the data from ${ }^{12} \mathrm{H},{ }^{13} \mathrm{C}-\mathrm{NMR}$ and 2D NMR (Table 1 and 2) were also confirmed the two tigloyl groups and confirmed by the carbon signals due to the acyl groups at $\delta 165.80$ and 166.94 which located at C-8 and C-11. The HMBC was exhibited obvious correlation peak between the two carbonyl (C- 
$\left.1^{\prime}\right)$ of 8-tigloyl and another carbonyl $\left(\mathrm{C}-1^{\prime}\right)$ of 11-tigloyl groups with $\mathrm{H}-7$ and $\mathrm{H}-11$ of the pregnane portion, respectively. The ${ }^{1} \mathrm{H}$ NMR spectrum displayed the presence of methine proton of the two tigloyl at $\delta 4.50$ and four methyl proton at $\delta 1.38,1.47,1.67$ and 1.72. However, the ${ }^{13} \mathrm{C}$ NMR spectrum of the two tigloyl groups showed the $4^{\circ}$-carbon signals at $\delta 166.94$ $165.80,128.86,128.86$, the methine carbon signals at $\delta$ 138.6 and 138.37, together with the four methyl carbon signals at $\delta 14.38,14.18,11.61$ and 11.34, correspondingly. (Table 2). Comparing the ${ }^{1} \mathrm{H}$ NMR spectroscopic data, especially the downfield shifted proton of $\mathrm{H}-11$ and $\mathrm{H}-12$ of this compound with Marsdenoside $\mathrm{D}^{[14]}$ and about coupling constants of $\mathrm{H}$ 11 and $\mathrm{H}-12$, the conclusion was drawn that the orientation of the two protons had shown in the structure. Considerably, the relationship between the dihedral angle and vicinal coupling constant ${ }^{3} \mathrm{~J}$ is given theoretically by the Karplus equation; ${ }^{3} \mathrm{Jab}=\mathrm{J}^{0} \cos ^{2} \mathrm{f}$ $0.28\left(0^{\circ}<\mathrm{f}<90^{\circ}\right)$ and ${ }^{3} \mathrm{Jab}=\mathrm{J}^{180} \cos ^{2} \mathrm{f}-0.28\left(90^{\circ}<\mathrm{f}<180^{\circ}\right)$. Thus, the relative configuration at $\mathrm{H}-11$ and $\mathrm{H}-12$ could be determined by the ${ }^{3} \mathrm{~J}_{11,12}, \mathrm{H}-\mathrm{C}-\mathrm{CH}(10.11 \mathrm{~Hz})$ coupling constant which indicated the two protons were located opposite side with dihedral angle $180^{\circ[15]}$. Based on the data described above, this compound was determined as 12-0-benzoyl-8, 11-ditigloyl-3 $\beta$, $8 \beta, 11 \alpha, 12 \beta$-pentahydroxy-pregn-14-ol,20-one,-3-0methyl- $\beta$-D-allopyranosyl $(1 \rightarrow 4)-\beta$-D-thevetopyranoside and being a new compound which has not been previously reported. In addition, this is the first study investigating the chondroprotective activity of PPG in cartilage explant model. Pro-inflammatory cytokine IL$1 \beta$ induced extracellular matrix in cartilage release to culture medium is the standard experimental model of cartilage degradation. The results show that at the low concentrations, which are active compound in ethyl acetate extract of Dregea volubilis, PPG inhibits IL-1 $\beta$ induced extracellular matrix degradation in porcine cartilage explant and decrease MMP-2 activity.

\section{CONCLUSION}

This study focused on the phytochemical of Thai medicinal plant together with biochemical evaluation. The results presented herein reveal the new polyoxypregnane glycosides derivative from the only species, Volubilis of the genus Dregea from has been most potent on chondroprotective effect. It is noted that the worthy finding of this study could be considered as a valuable economic medicinal natural products which helpful the osteoarthritis therapy to human health.

\section{ACKNOWEDGEMENT}

We gratefully acknowledge Center for Innovation in Chemistry (PERCH-CIC) for financial support and the National Research Council of Thailand (NRCT), The Lampang Rajabhat University, grants no. 006/2009 and we are also thankful to Dr. Kruawon Wongpaiboon for English editing

\section{REFFERENCES}

1. Panda, N., M. Nirup B., B. Sukdeb, S. Niranjan and K. Kazuo et al., 2003. Polyhydroxy pregnanes from Dregea volubilis. Tetrahedron, 59: 8399-8403. DOI: $10.1016 /$ j.tet.2003.08.063

2. Sahu, N.P., P. Nilendu, M. Nirup, B. Sukdeb, K. Kazuo and N. Tamotsu, 2004. Polyoxypregnane glycosides from the flowers of Dregea volubilis. Phytochemistry, 61: 383-388. DOI: 10.1016/S0031-9422(02)00260-1

3. Tteng, N.S., 1883. Dregea volubilis (Linnaeus F.) Bentham ex J.D. Hooker, Fl. Brit. India. FOC., 16: 250-251.

http://www.efloras.org./florataxon.aspx?flora_id=2 \&taxon_id $=200018603$

4. Smitinand, T., 2001. Thai Plant Name. Revised Edn., Pra Cha Chon Co., Ltd., ISBN: 9748838501, pp: 245.

5. Valke, D., 2008. Sneeze Wort. Flora of India. http://www.flowersofindia.net/catalog/slides/sneez e\%20wort.html

6. Bai, H., L. Wei, A. Yoshihisa, S. Tadaaki, W. Yuanshu and K. Kazuo. 2009. Twelve pregnane glycosides from Cynanchum atratum. Steroids, 74: 198-207. DOI: 10.1016/j.steroids.2008.10.007

7. Fenton, J.I., K.A. Chlebek-Brown, T.L. Peters, J.P. Caron and M.W. Orth, 2000. Glucosamine HCl reduces equine articular cartilage degradation in explant culture. Osteoarth. Cartil., 8: 258-265. DOI: $10.1053 /$ joca.1999.0299

8. Farndale, R.W., D.J. Buttle and A.J. Barrett, 1986. Improved quantitation and discrimination of sulphated glycosaminoglycans by use of dimethylene blue. Biochem. Biophys. Acta, 883: 173-177. DOI: 10.1016/0304-4165(86)903065

9. Kongtawelert, P. and P. Ghosh, 1989. An enzymelinked immunosorbent-inhibition assay for quantization of hyaluronan (hyaluronic acid) in biological fluids. Anal. Biochem., 178: 367-372. DOI: 10.1016/0003-2697(89)90654-4 
10. Blumenkrantz, N. and G. Asboe-hansen, 1973. New method for quantitative determination of uronic acids. Anal. Biochem., 54: 484-489. DOI: 10.1016/0003-2697(73)90377-1

11. Kleiner, D.E. and W.G. Stetler-Stevenson, 1994. Quantitative zymography: Detection of pictogram quantities of gelatinases. Anal. Biochem., 218: 325-329. DOI:10.1006/abio.1994.1186

12. Abdel-Sattar, E., F.M. Harraz, S.M.A. Abdullah Alansari, S. El-Mekkawy and C. Ichino et al., 2008. Acylated pregnane glycosides from Caralluma tuberculata and their antiparasitic activity. Phytochemistry, 69: 2180-2186. DOI: 10.1016/j.phytochem.2008.05.017

13. Dobolis, M., K.A. Golles, J.K. Hamilton, P.A. Rebers and S. Fred, 1956. Colorimetric method for determination of sugar and related substances. Anal. Chem., 28: 350-356. DOI: 10.1021/ac60111a017
14. Deng, J., Z. Liao, D. Chen and A.H. Marsdenosides, 2005. Polyoxypregnane glycosides from Marsdenia tenacissima. Phytochemistry, 66: 10401051. DOI: 10.1016/j.phytochem.2005.03.018

15. Lan, Y.H., C. Fang-Rong, Y. Jin-Hsien, Y. YuLiang and C. Yi-Ling et al., 2003. Cytotoxic styrylpyrone from Goniothalamus amuyon. J. Nat. Prod., 66: 487-490. DOI: 10.1021/np020441r 